\title{
Tester Status Report: April-June 1979
}

Charles F. Draut

Issued: August 31, 1979

\section{RECEIVED \\ JU! 011996 \\ OSTI}

\section{MOUND FACILITY}

Miamisburg, Ohio 45342

operated by

MONSANTO RESEARCH CORPORATION

a subsidiary of Monsanto Company

for the

U. S. DEPARTMENT OF ENERGY

Contract NO. DE-ACO4-76-DPOOO53 
A. MOUND MAKE ITEMS

I. Tester/testing support of timers, actuators, detonators, firing sets, transducers, isolators, and pyrospacers.

\section{PT3047 - Functional Testing of Explo- sive Timers}

The PT3047 is to be a replacement for the PT1347 timer tester which currently supports the bulk of destructive-testing of timers at Mound. These timer programs include the MC3038, MC3050, MC3155, MC3319, and the MC3348. This new tester, PT3047, will be significantly better than the old system by virtue of newer equipment and improved data acquisition and control.

TESTER ENGINEERS - Daniel R. Knick and John $A$. Kronenberger

Status. H. M. Barnett and N. F. Siska of SLA visited Mound on June 13-14, 1979, to assist in effecting an efficient project transition between Mound Product Tester Engineers D. R. Knick, J. A. Kronenberger, and F. R. Natschke. No significant transition problems were encountered during the PT3047 project status review meeting. The new $C D U$ fireset was triggered from the PT3047 which is shown in Figure 1 . Software to be used to test the timers is being written by Dan Knick and John Kronenberger. The programs for the data form generation and Geisha Data manipulations will be written by Tod A. Rapp. All designated spare parts ordered in March, 1979, have been received.

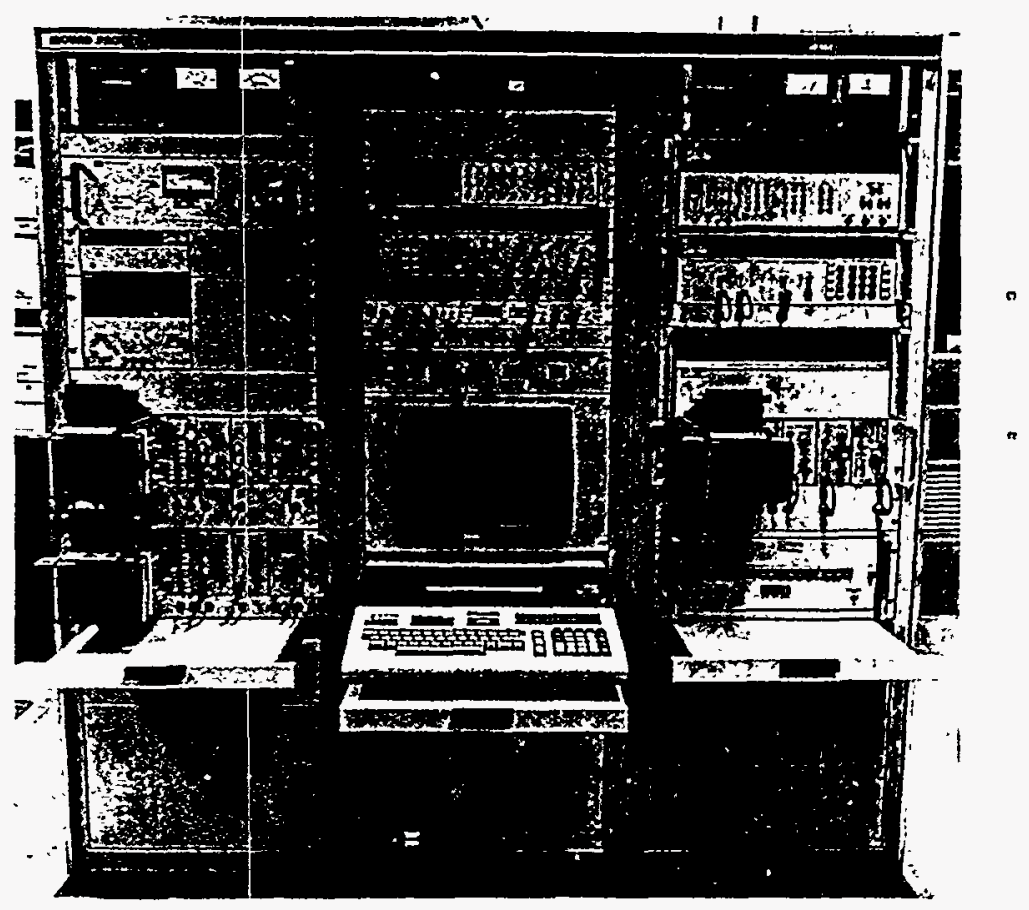

FIGURE 1. - The PT3047 will digitally record timer function time and peak pressure output; backup analogs of the same data will be recorded on oscilloscopes. The HP9845 programmable calculator will function as the test system controller and provide a variables data printout of the results of each test.

MT1049 - High Voltage Tester

The MT1049 is a replacement for the original MA2017 high-potential voltage tester and will be used to evaluate the MC3347 and MC3352 explosive isolators. The new tester will use a 743 KSR (Keyboard Send Receive) terminal for manual data entry and data printout. A Texas Instruments $990 / 4$ microprocessor will be utilized for process control and data acquisition.

TESTER ENGINEERS - Felton M. MCDOnald and Duane 0 . Page 


\section{DISCLAIMER}

This report was prepared as an account of work sponsored by an agency of the United States Government. Neither the United States Government nor any agency thereof, nor any of their employees, makes any warranty, express or implied, or assumes any legal liability or responsibility for the accuracy, completeness, or usefulness of any information, apparatus, product, or process disclosed, or represents that its use would not infringe privately owned rights. Reference herein to any specific commercial product, process, or service by trade name, trademark, manufacturer, or otherwise does not necessarily constitute or imply its endorsement, recommendation, or favoring by the United States Government or any agency thereof. The views and opinions of authors expressed herein do not necessarily state or reflect those of the United States Government or any agency thereof. 
Status. Because of the restart-up of the production of the MC2838 electrical assembly for the w70 program, Product Engineering recently requested that the current MA2017 hi-pot tester, which supports in-line testing of MC3347 and MC3352 isolators, be retained even after the "new" replacement MA2017 tester is completed and released for service. since both testers will be in existence concurrently, the "new" replacement. hi-pot tester was re-identified as the MT1049 hi-pot tester (AYE790272). The MT1049 tester is approximately $95 \%$ completed. The tester hardware is ready for system shakedown tests. No major shakedown problems are being anticipated. The projected delivery date for the Mr1049 tester is october, 1979.

A Qualification Evaluation Release was received on May 10, 1979, to release the present MA2017 hi-pot tester as acceptable for nondestructive testing of the transducer assembly, P/N 327339, for the MC3352 explosive isolator program.

\section{MA2018 - Capacitance Bridge Tester}

The MA2018 utilizes a commercial General Radio 1673 Automatic Capacitance Bridge to measure the capacitance of the transducer assemblies for the MC3347 and MC3352 explosive isolator programs.

Status. A Qualification Evaluation Release was received on May 10, 1979, to release the MA2018 capacitance bridge tester as acceptable for nondestructive testing of the transducer assembly, $\mathrm{P} / \mathrm{N}$ 327339, for the MC3352 explosive isolator program.
PT4030 - Resistance Tester

The PT $4030 \cdot$ is a resistance tester designed to measure resistance of several explosive components. This tester is an alternative to the PT2204 resistance tester.

\section{Status. A Qualification Evaluation} Release was received on May 8, 1979, to release the PT4030 resistance tester as acceptable for testing the MC3352 explosive isolator, $\mathrm{P} / \mathrm{N} 317151$.

$\frac{\text { PT3217 }}{\text { Isolators }}$ Destructive Tester for

The PT3217 is a destructive-test acceptance system which is used to qualify the MC3347 and MC3352 isolators at Mound.

Status. A Qualification Evaluation Release was received on May 10, 1979, to release the PT3217 destructive tester as acceptable for testing the MC3352 explosive isolator, $\mathrm{P} / \mathrm{N} 317151$.

\section{$\underline{\mathrm{PT} 3075}$ - Resistance Tester}

The PT3075 is a nondestructive tester designed to measure bridgewire resistance for numerous detonator programs and resistance of the MC3347 and MC3352 explosive isolator programs.

\section{Status. A Qualification Evaluation} Release was received on May 10, 1979, to release the PT3075 resistance tester as acceptable for testing the MC3352 explosive isolator, $\mathrm{P} / \mathrm{N} 317151$. 


\section{PT3118 - Destructive Tester}

The PT3118 is the destructive-test system used to qualify a number of pyrotechnic devices including the MC3004, MC3095, SA2401, SA2834 and MC2949. It uses two Biomation digitizers to digitize output pressure, firing voltage and current. Data are collected and analyzed by an HP9830 programmable calculator/controller. TESTER ENGINEER - David L. Badgley

Status. Modifications of the PT3118 to support the MC3095 detonator program were started in March after completion of Lot 10 MC3004 actuator testing. The modifications included interfacing the PT3118 to a Flash X-Ray unit and the altering of the fireset to generate a 20-A constant current fire pulse. Self-checking features were incorporated into the modifications in order to enhance and simplify calibration activities for the Pr3118. Operation of the ancillary Flash X-Ray system was successfully verified. A MC3004/MC3095 simulator was fabricated and utilized to verify the performance of the PT3118 tester prior to component "check-out" test firings.

The Engineering Qualification ( $E Q$ ) of the PT3118 destructive tester and ancillary equipment for support of the MC3095 detonator program was conducted on June 27-28, 1979. During $E Q$ of the destructive tester, a significant nofire transient pulse was observed that inadvertently fired a MC3095 detonator. At the PT3118/MC3095 close-out meeting, Mound and Sandia personnel mutually agreed the no-fire transient pulse should be eliminated prior to conducting the Accuracy and Precision (A\&P) Study on the PT3118 tester. A tentative reconvening of the $\mathrm{EQ}$ team was scheduled for the week of August 13. The PT3118 destructive tester is not required to test MC3095 detonators until November, 1979.

A Qualification Evaluation Release (QER) was received June 29, 1979, to release the PT3118 destructive-tester as acceptable for performing briagewire resistance, no-fire, and all-fire destructive testing of the MC3004 actuator, $P / N$ 315482-01. The re-EQ followed the aforementioned minor modifications of the Pr 3118 .

$\underline{\text { PT4025 }}-\underline{\text { MCCS/MC3048 Fireset Tester }}$

The PT4025 is a PDP $8 / \mathrm{m}$ computer-based automated tester used in the functional testing of the Multiple-code coded Switch (IMCCS) and the output switch in the MC3048 irireset.

TESTER ENGINEER - JOhn A. KrOnenberger

Status. The visicorder for the Pr4025 tester was received in June, and will be interfaced to the PT4025 magnetic tape recorder when time permits. The visicorder will add the capability to play back information that is stored on the magnetic tape recorder for display. This will enhance the users' ability to troubleshoot the item under test when a problem occurs.

PT403I - Flux, Hi-Pot, and Pulse Tester

The PT403I is a flux, high-potential and high-voltage pulse tester designed 
to evaluate the MC3106 transducer in accordance with Sandia Product Specification PS211585.

TESTER ENGINEER - Frederick W. Quigley

Status. This tester currently exists as the PT2163, which was obtained from Bendix/Kansas City. Cosmetic and technical changes will be made, and a new drawing package will redefine the tester as PT4031.

PT4034 - Dynamic Destructive Functional. Tester

The PT4034 is a destructive-test system that provides functional testing for the MC3106 transducer in accordance with Sandia Product Specification PS211585 and the MC3048 fireset in accordance with Sandia Product Specification PS211575. All tests will take place in a spin environment provided by a Trio Tech spinner.

TESTER ENGINEER - David L. Badgley

Status. The PT4034 destructive-test system consists of the basic PT 4034 test instrumentation system, fixtures which adapt the MC3106 transducer and the MC3048 firing set to the Trio Tech spinner, the UB0478 waveform digitizer, and the UB0466 Trio Tech spinner. SLI continues to develop and refine the twobay control, power-supply, and firepulse console which makes up the PT4034 test instrumentation system. The two Tektronix Model 7903 oscilloscopes have not been installed as of this reporting.

The two-bay, UB0478 waveform digitizer was an additional capability deemed necessary by SLI component personnel in order to obtain the output resolution required by the product specifications. This subsystem will use a PDP-11/34 computer for control. SLI is presently building the UB0478 digitizing subsystem utilizing a Tektronix Model 7912 waveform digitizer. The UB0478 with the 7912 digitizer will be developed with the PT4034 spin test system. The 7912 digitizer will subsequently be removed and replaced with a Tektronix, Model 7612, waveform digitizer when the 7612 's become available. SIL expects a field model of the 7612 to be available to them this Fall. They expect to receive their production 7612 unit in February or March, 1980. John Anderson projects the delivery of the PT4034 spin test system, fixtures to adapt MC3106/MC3048 components to the Trio Tech spinner, and the UB0466 Trio Tech spinner to Mound by the end of CY79. The UB0478 digitizing subsystem will probably be delivered in April, 1980.

\section{PT4035 - Polarity and Resistance Testex}

The PT4035 is a polarity and resistance tester designed to test the MC3106 transducer in accordance with Sandia product Specification PS211585.

TESTER ENGINEER - David F. Mayers

Status. R. F. Facer, SLL, D. F. Mayers, F. R. Natschke, and R. C. D'Amico participated in a Conceptual Design Review on the W79 PT4035 polarity and resistance tester on April 3, 1979. The design proposal, concepts, and delivery schedule were acceptable to Mr. Facer. The design alterations requested during the design review 
were of minor consequence and presented no significant deviation to the original tester concept design. Equipment procurement was authorized in support of this product tester. An internal Mound Design Review for the PT4035 polarity and resistance tester was held on May 11, 1979. Minor design recommendations were incorporated into the original PT4035 preliminary design proposal, and the updated PT4035 design proposal was mailed to R. F. Facer at SLL on May 15, 1979.

The initial design of the component test fixture/safety chamber that supports the PT4035, PT4038, PT4039 (W79) product testers was initiated. The component holding fixture will be mounted on a sliding tray which permits the operator to safely and correctly cable the unit under test (UUT) while external to the safety chamber. These elaborate safety measures for a nondestructive test system are required due to the unique hazard potential of the W79 components being tested.

\section{PT4038 - High Potential Voltage Tester}

The PT4038 is a high-potential tester designed to test the MC3048 fireset in accordance with Sandia Product Specification PS211575. To meet this specification, the tester will provide test voltages ranging from 500 to 4000 volts. Two of these testers will be required. TESTER ENGINEER - David F. MayerS

Status. R. F. Facer, SLL, D. F. Mayers, F. R. Natschke, and R. C. D'Amico participated in a Conceptual Design Review on the W79 PT4038 hi-pot tester on
April 3, 1979. The design proposal, concepts, and delivery schedule were acceptable to $\mathrm{Mr}$. Facer. The design alterations requested during the design review were of minor consequence and presented no significant deviation to the original tester concept design. Equipment procurement was authorized in support of this product tester.

An internal Mound Design Review for the PT4038 hi-pot tester was held on April 23., 1979. Minor design recommendations were incorporated into the original PT4038 preliminary design proposal, and the updated PT4038 design proposal was mailed to R. F. Facer at SLL on May 10, 1979. The initial design of the component test fixtures/safety chamber which supports the PT4035, PT4038, PT4039 (W79) product testers was initiated.

PT4039, MT1043 - Resistance Testers

The PT4039 is a resistance tester for the MC3048 fireset. It provides the capability to measure and record a number of continuity and resistance readings up to 20 megohms. The MT1043 is a development version of the PT4039. TESTER ENGINEER - John A. Kronenberger

Status. R. F. Facer, SLL, D. F. Mayers, F. R. Natschke, and R. C. D'Amico participated in a Conceptual Design Review on the W79 PT4039 resistance tester on April 3, 1979. The design proposal, concepts, and delivery schedule were acceptable to Mr. Facer. The design alterations requested during the design review were of minor consequence and presented no significant deviation to the original tester concept design. Equipment procurement was 
authorized in support of this product tester. A subsequent Mound internal Design Review was held on May 11, 1979, for the PT4039 resistance tester. The original PT4039 preliminary design proposal was rejected by the Design Review Committee for not being cost effective. A subsequent PT4039 Design Review was held on May 18, 1979, to assess the cost effectiveness of the redesigned alternative proposals. The most effective design selected was submitted in JulY for review by R. F. Facer and J. S. Anderson, at SLL. The initial design of the component test fixture/safety chamber which supports the PT4035, PT4038, PT4039 (W79) product testers was initiated.

\section{PT4042 - Switch Change Tester}

The PT4042 was designed to effect the. MC2907 MCCS status changes required to accomplish MC3048 fireset functional tests. Two of these testers are beine; built for Mound by SLI.

TESTER ENGINEER - David L. Badgley

Status. SIL was about ready in midJune to check out the first of two PT4042 functional testers for the MC3048 fireset program. Both PT4042 testers should be ready to ship to Mound by the end of July, 1979. J. S. Anderson, SII, Org. 8166, suggested the Mound Tester Engineer visit SLL during their checkout oI the PT4042 to review the calibration and operational procedures prior to shipment.
W79 - Test System

The 679 Test system is an open setup test facility for the static destructive testing of the MC3106 transducer.

TESTER ENGINEER - Frederick W. Quigley

Status. The MC3106 test set which will supply the arm current and fire pulse to the item under test was being fabricated in mid-June and should be completed by July 9, 1979. This test set will be incorporated into the "C" tank test system as part of the MC3I06 static destructivetest system for the 779 program.

\section{PT3180 - Electrostatic Sensitivity Tester}

The PT3180 is a general purpose electrostatic sensitivity tester designed to meet the requirements of the Sandia Electrostatic Sensitivity Testing Specification (SS-302365), i.e.; $20 \mathrm{kV}$, $500 \Omega ; 600 \mathrm{pF}$.

TESTER ENGTNEER - John A. Kronenberger

Status. An Engineering Qualification (EQ) of the Pr3180 electrostatic sensitivity tester and ancillary equipment in support of the MC3095 detonator program was conducted on June 26, 1979, by L. Learson and A. K. Jacobson of SIA. An Accuracy \& Precision Study per PS315770 will be conducted during the week of July 23-27 before a Qualification Evaluation Release (QER) will be issued. 


\section{MT1042 - Development Tester}

The MT1042 is a development tester required by the Advanced Component Development Section at Mound to serve as a general purpose ETR tester for a number of development activities. It will be similar to the MT1035/MA2016, but will use an HP9845A calculator in lieu of the HP9830 calculator. It will also have the capability of accepting ETR pulses of various amplitudes and widths generated from commercial or specially designed pulsers.

TESTER ENGINEER - David L. Badgley

Status. The MTl042 development tester was delivered to A. C. Munger of the Advanced Component Development Section at the end of last quarter, and is operating properly. The Biomation 1015 digitizer was interfaced to the multi-programmer; this permits the Biomation data to be read with either a HP9825 calculator or the HP9845A calculator. The MT1042 tester was subsequently modified to expand the current range for electro-thermal response (ETR) testing in support of a component surveillance program in the Advanced Devices Department. The expanded ETR current range is now 50 milliamperes to 1.2 amperes, and the resistance measuring limit range was extended to 19.99 ohms.

MT1018A - Remanent Charge Tester

The MT1018A is a remanent charge tester used for the MC3027 transducer program. TESTER ENGINEER - John A. Kronenberger
Status. An Engineering Verification (EV) was performed on the new MTI018A charge tester in April. In the interest of regaining the MC3027 production schedule and maintaining a backup tester, Product Engineering requested the current MT1018A remanent charge tester be retained after the new revised MT1018A tester was completed and released for service. Since both testers would be in existence concurrently, the "new" remanent charge tester was re-identified as the MT1048 remanent charge tester. The new MC3027 charge tester (MT1048) will require different drawing and manual numbers. Revisions to existing specifications and drawings relating to the charge testers will have to be resolved. In order to avoid future problems the remanence charge function ONLY in the "Old" MT1018A tester will be disabled. Mound's product engineer will notify the tester engineer when the "old" MTl018A tester will be available for remanence charge "neutering". In conversation with Sandia personnel, they said they will not require the new charge tester to be Engineering Qualified, but would like to see schematics and the Accuracy and Precision Study data of the new tester as an information evaluation. An Accuracy and Precision Study on the . MT1048 tester will be conducted during the week of July 23-27, 1979.

\section{MT1034 - High-Potential Voltage Tester}

The MT1034 high-potential voltage tester was designed to check the 1E33 detonator/ cable assembly for voltage breakdown in ambient condition and in a vacuum which simulates a high altitude condition.

TESTER ENGINEER - Duane O. Page 
Status. The MT1034 tester was

indicating unusually high reject rates when hi-pot testing 1 E33 detonator and cable assemblies. To correct this condition, circuit modifications were made to the high voltage breakdown detector and the test fixture was isolated from ground. Testing of the IE33 assemblies was resumed on April 23, 1979, with reject rates near normal levels for this test.

MT1047 - Bridge Function Tester

MT1047 is a destructive system to functionally test the IE35 bridged header while monitoring the $\mathrm{dv} / \mathrm{dt}$ action of the bridge.

TESTER ENGINEER - Frederick W. Quigley

Status. The MT1047 bridgewire function tester for the lE35 detonator/cable assembly program was completed and released to the user in May. Checkout of the tester will be performed at the discretion of the product engineer, but is tentatively scheduled for August. The bridgewire testing requirement for the $1 E 35$ has been temporarily omitted from the product specifications.

\section{PT1619 - Destructive Tester}

The PT1619 is a destructive tester for electrically activated detonators. It tests the following attributes:
a. Bridgewire resistance.
b. Bridgewire burst current.
c. Time to maximum bridgewire voltage.

d. Time from start of current flow to maximum bridgewire voltage.

e: Time from maximum bridgewire voltage to start of pulse switch.

TESTER ENGINEER - JOhn A. Kronenberger

Status. Pilot Lot testing of the MC3366 detonator utilizing the modified PT1619 destruct tester was successfully completed in May. Operator convenience alterations to the proposed PT1619 Calibration and Operation Procedures were incorporated into the final version of the PTI619 procedures.

\section{Tester support of the LLL Ceramic Header.}

Testing Reguirements for LLL Ceramic Header

There are three testing requirements for the ILL Ceramic Header: 1) highpotential voltage application to the unbridged head; 2) resistance measurement of the bridge circuit at three locations; and 3) destructive bridgewire functioning. The system for destructive bridgewire functioning will require equipment to digitize the current and voltage waveforms and will utilize a dual trace oscilloscope for backup data documentation.

MTl044 - High Potential Tester

The MT1044 is a high-potential tester for the ceramic head of the MADI049 program. The tester applies an $8 \mathrm{kV}$ level to the unbridged header. A "Magsense" circuit is utilized to 
detect short pulse breakdown within the header. A test/holding fixture designed by GEND will be adapted to the MTl044.

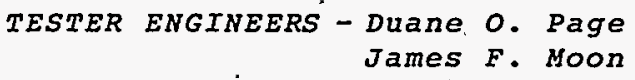

Status. The scheduled delivery date for the MTI044 hi-pot tester is being projected for mid-August. This delivery date was constrained by the availability of the Texas Instrument 5TI 1023 Sequence Programmer. The defective sequence programmer was returned to the manufacturer for repair. The MTl044 hi-pot tester was designed and fabricated to effect and enhance the ceramic technology transfer program at Mound.

\section{$\underline{\text { MTI045 - Resistance Tester }}$}

The MT1045 is a resistance tester designed to evaluate the ceramic header of the MAD1049 program. The Tester Section will design and fabricate a resistance fixture to accompany the MT1045 resistance tester.

\section{Status. Procurement of equipment} for this tester is deferred to FY80 because of current budgetary constraints.

MT1046 - Functional Tester

The MT1046 is designed to destructively test and evaluate the performance characteristics of the bridgewire element on the ceramic header used in the MAD1049 program. A waveform digitizer and a computer will be utilized to process the pertinent bridgewire performance data.
Status. An interim functional testing system is being furnished by Mound's Advanced Component Development Section. The MAD1049 testing requirements are undefined. The final conceptual design is on hold. Current budgetary constraints were causing procurement of equipment to be deferred to FY80.

\section{Tester support of the Nuclear Component Evaluation Operations}

ICTS

The Laboratory Component Test System (ICTS) is a microprocessor-based test system which supports Component Evaluation Operation activities at Mound Facility. It is based upon a modular distributed microprocessor system for control and data acquisition. It will have the capability to support existing as well as the newest weapon sy.stem components.

PROJECT ENGINEERS - Francis A. Koehler (Leader), David $F$. Mayers and James $F$. Moon.

PROJECT MANAGER - RON C. D'AmiCO

Status. Removal of the flat ribbon cables between the Data Microprocessor and the Analog station was completed in order to convert the original parallel connection configuration to a bus configuration. The bus configuration and its interface eliminated the need for the data microprocessor extended bus driver circuitry and nineteen $I / O$ cards. 
Assistance was provided to the CEO Group in setting up the Sandia $A C$ Fireset to effect system 9 testing endeavors. This setup arrangement utilized an oscilloscope in the LCTS main frame to monitor current demands during the system 9 test. This support from the Tester Design and Fabrication Group was in addition to the normal efforts defined in the LCTS PERT network. The Manual Fire Panel chassis supplies both Safing relay signals and Fireset firing command signals for Test station 4 fireset. This chassis was successfully bench tested and installed in $5 W-208$. Cables connecting the walkin hood to the LCTS fireset rack for TS-4 were completed. The LCTS current Monitoring chassis was completed.

P. D. Bantz participated in the evaluation of the NEFF data acquisition system. Due to the limited time allowed for evaluation, coupled with the budget constraint, a NEFF 620 system was ordered. Evaluation of the original system is ongoing in hopes of eliminating some of the deficiencies exposed during the statistical evaluation of the hardware.

Significant progress was made in setting up the LCTS for System 7, Version 4 testing requirements. During shakedown testing of the UA1571 Relay Chassis, wiring errors were detected and corrected. The Ten Channel Bridgewire Voltage Measurement and Analog Interface circuits to the Phoenix Analog-to-Digital cards were designed. The interface chassis for system 7,
Version 4 testing requirements is approximately 308 completed. The Analog interface circuit board was fabricated by Tester Personnel.

Weapon Select Panel alterations are being implemented due to the elimination of the System 7, Version 3 requirement in Iieu of the System 7 , Version 4 requirement. The Weapon Select Panel alterations consist of reprogramming an EPROM on the UA1743 Weapon Select logic board and modifying hardware on the UAI744 Weapon Select interface card. The Weapons PROM software program for the System 7, Version 4 requirement is approximately 608 completed.

In order to effect the efficient delivery of Test Station 1 and Test Station 2 by July, 1980, R. C. D'Amico will serve as the LCTS Project Manager. F. A. Koehler will continue to serve as the LCTS Project Engineer. The July, 1980, delivery of Test Station I and 2 will also include in its scope efforts by the Tester Design and Fabrication Group to establish and effect a contingency for Test Station 4 via an open setup utilizing the MA2010 and NEFF system, and its appropriate ancillary equipment/Test station interfacing.

The comprehensive "state-of-the-project" evaluation on the LCTS project and its associated PERT network was completed in June. Milestone Targets were chosen to monitor LCTS progress. Milestone Target status will be published each week as an integral part of a Mound 
ICTS weekly report in addition to this quarterly reporting. Milestone Target progress will be evaluated and measured via completion activities "checked off" of a ICTS Action PIan and PERT network. A listing of Milestone Target Definitions with its associated block diagram sumarizing the Milestone Target activities in laymen's terms is Repicted below.

\section{MILESTONE TARGET DEF'INITIONS}

MTl: Test Station $4 \mathrm{~W}$. Wood support completed.

MT2: Microprocessor system completed.

MT3: Main Computer/Microprocessor/ Datel Voltage and Analog Systems completed; System 2 completed.

MT4: Standards Iaboratory \& Data verification checkout completed.

MT5: Digital section of the Analog System completed.

MT6: Total Analog System completed.

MT7: Weapons PROM System completed; System 7, Version 4 installed but not verified.

MT8 : Fireset System and system 9 completed.

MT9: Standards Laboratory Verification activities 90 percent completed.

MTI0: SW-210 System fully functional in support of Test Stations $1 \& 2$.
LCTS MILESTONE TARGET SPECIFICS

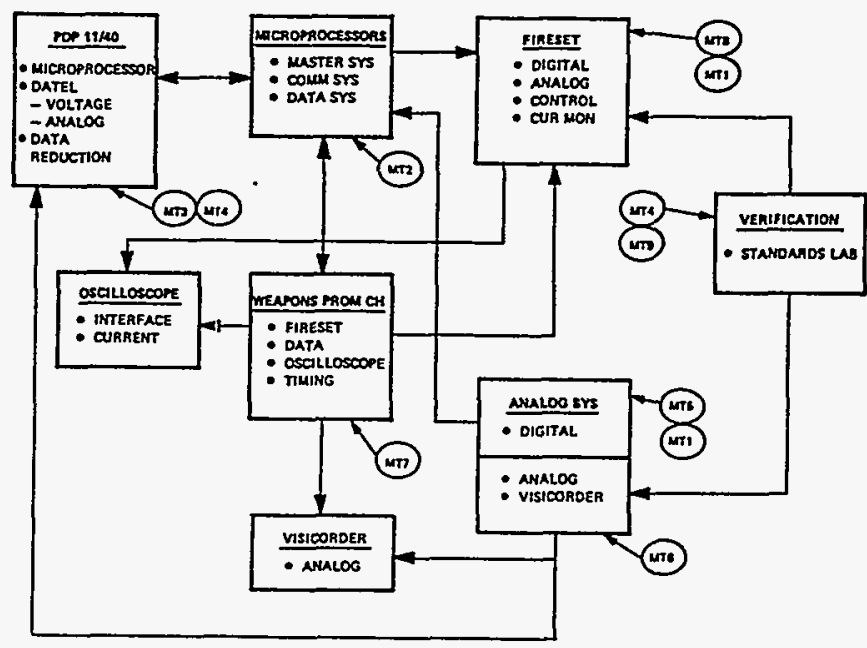

On July 2, 1979, Milestone Target MT1 was successfully completed. This Milestone Target (MTl) represented the Tester Design and Fabrication Group's commitment in bringing Test station 4 Firesets and their associated monitoring and cabling on line for use by the CEO Group. A Milestone Target Status as of July 2, 1979, is shown below.

\section{MILESTONE TARGET STATUS}

\begin{tabular}{|c|c|c|c|c|}
\hline $\begin{array}{l}\text { MIIE- } \\
\text { STONE } \\
\text { TARGEI }\end{array}$ & $\begin{array}{c}\text { PERCENT } \\
\text { COMPILEIED }\end{array}$ & $\begin{array}{l}\text { STATUS } \\
\text { TARGET }\end{array}$ & $\begin{array}{l}\text { TARGET } \\
\text { DATE }\end{array}$ & REMARKS \\
\hline $\mathrm{Mrl}$ & 100 용 & DONE & $07 / 13 / 79$ & $07 / 02 / 79$ \\
\hline $\mathrm{MT2}$ & 305 & OK & $09 / 05 / 79$ & \\
\hline$M T 3$ & $0 q$ & & $10 / 22 / 79$ & \\
\hline MT4 & $0 \%$ & & $02 / 01 / 80$ & \\
\hline MI5 & $0 \%$ & & $01 / 10 / 80$ & \\
\hline MT6 & $20 \%$ & OK & $01 / 10 / 80$ & \\
\hline MI7 & $19 \%$ & OK & $03 / 10 / 80$ & \\
\hline MT8 & 0 옹 & & $03 / 18 / 80$ & \\
\hline Mrr9 & $0 \%$ & & $01 / 10 / 80$ & \\
\hline MIIO & 198 & OK & $07 / 31 / 80$ & \\
\hline
\end{tabular}




\section{Tester Support of the Nuclear SW Analytical Operations}

\section{E82280 - Process Control for Thermal Decomposition of Metal Hydrides}

This system is a microprocessor-controlled Thermal Gas Rack used as an analytical technique for measuring the amount of hydrogen contained in metal hydrides.

PROJECT ENGINEER - FranCIS A. KOehleI Status. The design of the main control panel for the gas rack in SW-219 has been initiated. This control panel contains provisions for either automatic (microprocessor) or manual control of the gas rack. The control panel is being fabricated by a local firm and should be at Mound by the second week in August. With this panel, manual control of the gas rack can be initiated by mid-September. A cabinet was procured for installation of the Motorola Micromodule and associated interface hardware.

Software supporting the infrared heater temperature measuring device is being optimized and will eventually be incorporated as a subroutine in the mainline of the gas rack software program. The gas rack interface sard cage and EPROM card have been designed and are being fabricated. The main solenoid bank was installed and wired to the solid state relays. These relays are connected to the microprocessor and serve as the interface to the real world.

\section{B. MOUND BUY ITEMS}

I. Tester/testing support of products at Unidynamics/Phoenix, Inc.

$\underline{\text { PT3237 - Bridgewire and Insulation }}$

The PT3237 is a tester capable of bridgewire resistance, insulation resistance, and continuity loop measurements. This tester is similar to the PT3102 tester currently at Unidynamics and will be used as a backup or an alternate.

TESTER ENGINEER - C. Keith OhleT

Status. An Engineering Verification and an Accuracy and Precision (A\&P) Study were conducted on the PT3237 hi-pot and resistance tester at Unidynamics/Phoenix, Inc. by $V$. S. Wenglikowski and $C$. R. Klohe of the Mound Tester Documentation and Control Group. The A\&P Study was conducted to confirm the PT3237 as acceptable for testing the MC2943, MC2987, MC3002, MC3133 and MC3196 B-item programs at Unidynamics/Phoenix. An Engineering Qualification for the test setup.of the PT3237 to support the MC3196 detonator program was tentatively scheduled with L. Learson, SLA-Q\&A, for the week of September 4, 1979. Engineering Qualifications for the PT3237 to support the MC2943, MC2987, MC3002, and MC3133 programs have been postponed at the Product Engineer's request until September, due to a lack of funds. 
UA1596 - Pressure Time Module

The UA1596 is a pressure time module used in conjunction with the Pr3104 and PT3240. testers to measure the pressure output of the MC3002 gas generator and the force output of the MC2949A actuator.

TESTER ENGINEER - C. Keith Ohler

Status. The calibration procedure for the UA1596 pressure time module, which will support the MC2949A actuator program at Unidynamics/Phoenix, was completed in April.

\section{PT3240 - Low Level-AlI Fire Tester}

The PT3240 is a low-energy destructivetester used on a number of B-items fabricated at Unidynamics/Phoenix. The PT3240 is a second generation version of the PT3104 with the following capabilities: bridgewire resistance measurement; no-fire; no-fire degradation; and constant current fire testing.

The PT3240 is a modularized tester consisting of a series of standardized units to be used together. The modular units are 1) the mainframe, 2) discrete test modules for a given product, and 3) a discrete operating program tape for a given product. The mainframe consists of power supplies; an oscilloscope and camera for measuring the current and voltage waveforms of the product unit under test; a control chassis including a M6800 microprocessor system; an alphanumeric display unit, which serves an an interface to the operator (it gives the operator instructions and provides system status); a plug-in panel to accept the various discrete test modules; a cassette tape deck to load the program/product operating tapes into the microprocessor memory; and a digital panel meter to measure and display bridgewire resistance and no-fire current. The mainframe of the PT3240 tester remains the same regardless of the product or number of different products tested. It will be calibrated and maintained as a stand-alone, Engineering Qualified (EQ) unit. The mainframe will not have to be re-EQ'd as additional products are placed on the tester. The test modules contain the required electronics to meet the given product specification fire pulse and no-fire pulse requirements. The modules contain a decode board which allows the tester mainframe to recognize each module as the appropriate one to test a chosen product. The product operating program tape is the intelligence for the tester mainframe in that it loads the required testing sequence into the mainframe along with the module requirements for the product to be tested.

TESTER ENGINEER - C. Keith Ohlex

Status. A software program was developed to shake down and verify the performance of the PT3240 D-Tester. The essence of the software program is a diagnostic test procedure utilizing the tester's own microprocessor to check its functions and those of the system's mainframe. The diagnostic program successfully detected and isolated three system malfunctions. These malfunctions were minor and were easily serviced. MC3196 Product Specification changes made in April necessitated a re-EQ of 
the MC3196 D-Test system. An EQ of the PT3240 D-Test system for the MC3196 program will be conducted in September. All software programs and operation (AF) and calibration (CP) procedures for the PT3240 test system in support of the re-EQ of the MC3196 detonator program were completed. An Engineering Verification of the PT3240 test system was conducted at Mound prior to its shipment to Unidynamics/Phoenix, Inc. The PT3240 low level-all fire tester, which is a second generation version of and which will be used as an alternative to the existing PT3104 tester at Unidynamics, was shipped from Mound to Unidynamics/Phoenix the week of June 18-22, 1979. The tester arrived at Unidynamics/Phoenix without damage. D. L. Badgley, C. K. Ohler, and H. I. Parker will set up and test the PT3240/ UA1538 tester combination in July in preparation for $\mathrm{EQ}$ for acceptance testing for the MC3196 program. V. S. Wenglikowski is scheduled to conduct an Accuracy and Precision Study of the PT3240 in August. Other weapons components planned to be Engineering Qualified (EQ) on the PT3240 are the MC2949A actuator and the MC3089 igniter by October, 1979, and the MC2848 marker. by February, 1980. The tester is shown in Figure 2.

\section{PT3105 - High Level-All Fire Tester}

The PT3105 is a high-energy all-fire destructive-tester used on a number of B-items fabricated by Unidynamics/ Phoenix. The PT3I05 is a tester providing a 70-amperes, 2.5 microsecond pulse for all-fire testing. The tester also provides low amplitudes and shorter pulses for no-fire testing. TESTER ENGINEER - C. Keith OhIer

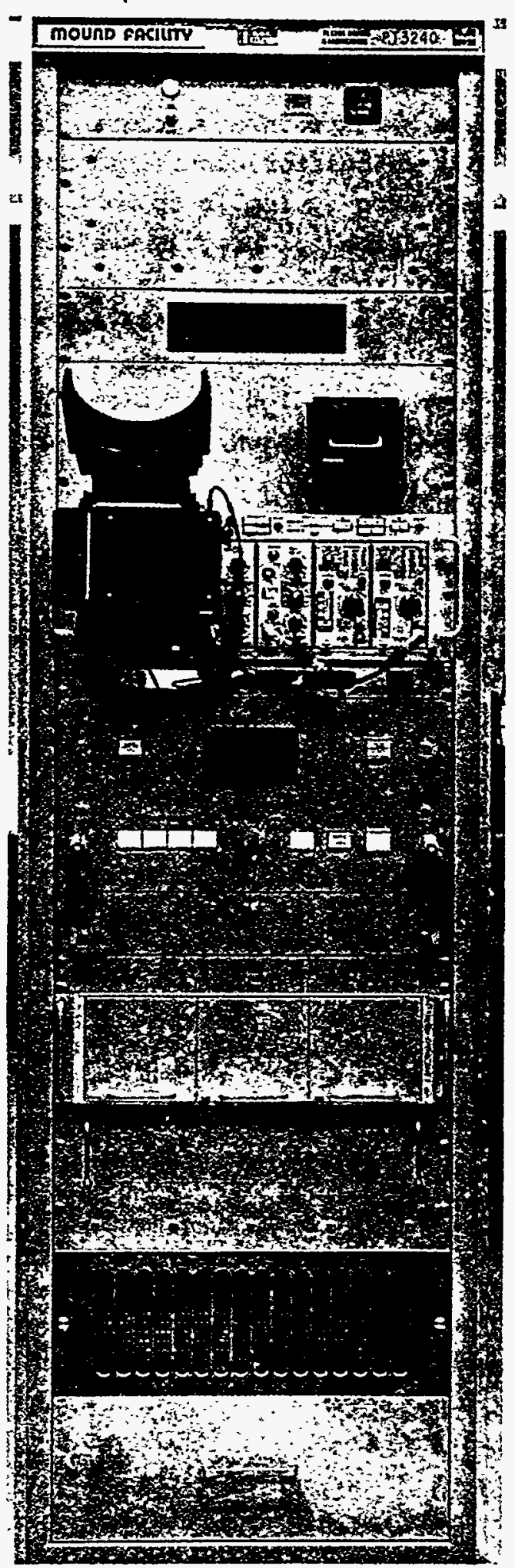

FIGURE 2. - The PT3240, single bay, tester measures bridgewire resistance, performs no-fire testing; no-fire degradation testing; and constant current fire testing. 
Status. The software program for the UA1538 calculator controlled data acquisition system in support of the MC3196 detonator program was completed. Engineering Qualification for the test setup of the PT3105/UA1538 system to support the MC3196 detonator program has been scheduled with Lacey Learson, SLA-Q\&A, for the week of September 4, 1979.

\section{PT3219 - Electrothermal Response Tester}

The PT3219 electrothermal response tester was delivered to support MC3196 and MC29.49A testing at Unidynamics/ Phoenix. This ETR tester is capable of remote operation when coupled with the UAI538 calculator controlled data system. This tester utilizes a Motorola M6800 microprocessor system to control all the timing and data transfer activities to the UAl538 system.

TESTER ENGINEER - David L. Badgley

Status. R. W. Hurd had previously requested an electrothermal response (ETR) testing capability for the ER322 component at Unidynamics/Phoenix, Inc. Software for the PT3219/UAA1538 system at Unidynamics was to be modified to support the new ETR testing specification for the ER322 LASL product. Unidynamics personnel was to supply the ER322 test fixturing. This request for testing support has been placed on hold.

\section{UAI538 - Calculator Controlled Data} Acquisition System

The UAl538 is a calculator controlled data acquisition system used in conjunction with the PT3104, PT3240, and
PT3105 testers to digitize and analyze resistance after firing ( $R A F$ ) data on the MC2987 torch. The UAI538 will also be used in conjunction with the PT3219 tester for electrothermal response testing of the MC2949A actuator and possibly the MC3196 detonator.

TESTER ENGINEER - C. Keith ohler

Status. The design changes to the UA1538 data acquisition system at Unidynamics/Phoenix, Inc., will initially support the MC3196 and MC2949A programs. The hardware modification implementation was completed in June, 1979. No major implementation difficulties were encountered. The software program for the UAl538 calculator controlled data acquisition system in support of the MC3196 detonator program was completed.

\section{PT3211 - Spin Tester}

The PT3211 was originally designed to provide for destructive testing and electrothermal response testing of the MC2949A actuator under spin environment. The spin-environment is accomplished by mounting the component in a Trio Tech spinner.

TESTER ENGINEERS - David L. Badgley

$$
\text { C. Keith ohler }
$$

Status. The reconditioned spindle/slip ring assembly has been remounted in the Trio Tech spinner at SLA, and the system is now operating. All fixturing required to adapt the MC2949A actuator to the spinner for passive and destructive testing under a spin environment is completed. The Trio Tech spinner and ancillary fixturing will be shipped to Unidynamics/Phoenix by the end of August; 
it should be installed and operational by the end of September, 1979. A. C. Strasburg, SIA 2514, has requested access to the spinner system for two weeks before the system is shipped to evaluate methods to decrease slip ring noise thus permitting the gathering of meaningful ETR data. The spare spindle/ slip ring assembly for the Trio Tech spinner is expected to be available for backup use by late October, 1979. The slip rings from Lebow are the delay; they are expected by october 5, 1979. Trio Tech will then mount the slip rings onto the spindle and checkout the spindle/slip rings as an assembly.

P. L. Johnson of Mound's Product Engineering Section has advised Unidynamics/Phoenix personnel of the space and utilities requirements for installation of the Trio Tech spinner. Examination of available space near the destructive testing areas identified two possible locations for the spinner, 1) anteroom to the explosive testing chamber, and 2) the northwest corner of the testing area currently utilized as a janitor closet. Either of these locations would permit product testers to be located within 10-15 feet of the spinner so as to minimize cable lengths. Facility modifications should be minimal since spinners need only be barricaded to exclude personnel during testing. Jim Kannolt of SLA assured Mound that the spinner cabinet enclosure has sufficient strength to contain any accident involving the spinner and its internal component fixturing. 


\title{
TESTER STATUS REPORT DISTRIBUTION
}

\author{
EXTERNAL \\ J. N. Boyer, DAO, DOE \\ G. R. Gartrell, DAO, DOE \\ M. D. Boyd, LASI, org. WX-7 \\ R. N. MCCormick, LiASI, Org. WX-7 \\ W. H. Meyers, LASI, Org. WX-7 \\ N. A. Schneider, LLI, Org. 9775 \\ J. R. Stroud, LLI, Org. 9775 \\ R. E. Zoret, ILL, Org. 9781 \\ D. H. Anderson, SLA, Org. 2510 \\ H. M. Barnett, SLA, Org. 2166 \\ J. T. Hillman, SIA, Org. 9515 \\ J. E. Kennedy, SLA, Org. 2513 \\ E. A. Kjeldgaard, SLA, Org. 2515 \\ C. B. McCampbell, SLA, Org. 2310 \\ W. G. Perkins, SIA, Org. 2516 \\ M. A. Rumsey, SLA, Org. 2514 \\ N. F. Siska, SLA, org. 2166 \\ T. Starr, SLA, Org. 9526 \\ B. H. Van Domelen, SLA, Org. 2514 \\ J. S. Anderson, SLL, Org. 8166 \\ K. L. Burris, SLI, Org. 8166 \\ R. F. Facer, SLI, Org. 8166 \\ . D. M. Pierce, SLI, Org. 8166 \\ J. R. Clement, MRC @ $U / P$ \\ R. C. Collins, MRC @ U/P

\section{INTERNAL}

M. E. Babcock

D. L. Badgley

J. R. Brinkman

R. C. D'Amico

R. J. DeSando

C. F. Draut (12)

G. E. Early

R. A. Fischbein

J. O. Hey

R. J. Huss

P. I. Johnson

F. A. Koehler

J. A. Kronenberger

J. F. Madden

D. F. Mayers

J. F. Moon

C. K. Ohler

D. O. Page

F. W, Quigley

D. R. Spangler

H. L. Turner

D. E. Wendeln

v. S. Wenglikowski 